\title{
Reduction in Children's Impulsivity Enhances Performance in Mathematics, but not English language: Evidence for Impulsive Behaviour Modification Using Cognitive Modelling
}

\author{
Eunice Torto-Seidu $^{1} \mathbb{C}^{\mathbb{C}}$, Ivy Kesewaa Nkrumah ${ }^{1^{\star}} \mathbb{( \mathbb { C }}$, Lebbaeus Asamani $^{1} \mathbb{C}^{\mathbb{C}}$
}

${ }^{1}$ University of Cape Coast, GHANA

*Corresponding Author: ivy.nkrunmah@ucc.edu.gh

Citation: Torto-Seidu, E., Nkrumah, I. K., \& Asamani, L. (2021). Reduction in Children's Impulsivity Enhances Performance in Mathematics, but not English language: Evidence for Impulsive Behaviour Modification Using Cognitive Modelling. Mediterranean Journal of Social E Behavioral Research, 5(3), 67-77. https://doi.org/10.30935/mjosbr/11338

\begin{abstract}
Test responses are mostly the chief basis for diagnosis, but educational appraisals of learners who experience difficulties mostly fail to account for the length of time the learner employs to respond to cognitive tasks. Impulsive children have been shown to experience challenges in school, not because they are less intelligent than the nonimpulsive ones, but because of their fast conceptual tempo. This study employed a cognitive modelling procedure in attempt to reduce impulsivity in children, and subsequently enhance their performances in English language and Mathematics. A total of 93 primary four pupils who had been identified as impulsive, participated in the study. They were divided into four groups using the Solomon Four Group Experimental Design. The findings were that the experimental groups showed a reduction in impulsivity relative to the control groups at posttest and delayed posttest measures. The reduced impulsivity in the experimental groups translated into improved performance in Mathematics but this was not observed in the subjects' performances in the English language. The results provide preliminary support for the efficacy of cognitive modelling training intervention as a mechanism for reducing impulsivity in children and enhancing their performance in Mathematics.
\end{abstract}

Keywords: impulsivity, cognitive modelling, academic performance

Received: 11 Aug. $2021 \bullet$ Accepted: 7 Sep. 2021

\section{INTRODUCTION}

Investigations on school-age children have demonstrated the intraindividual stability and inter-task generality of a disposition called 'impulsivity'. Impulsivity is the generic term that describes the tendency to act on the spur of moment without deliberation, planning and weak self-regulation capacity (Carver, 2005). Impulsive children seldom stop to think before they completely understand instructions, tend to come forth with the first answer they can think of, and call out repeatedly in class (typically with wrong answers). It is even not rare to spot children who after signalling intention to respond, stand up and stare blankly at the teacher- apparently having forgotten the purpose for standing up in the first place. Impulsive patterns are the core features of hyperactivity (Barkley, 2006), some kinds of aggressiveness (Fontaine \& Dodge, 2006), risky health behaviours (Zapolski, Cyders, \& Gregory, 2009) and other illogical actions. Impulsivity as a behaviour has also been associated with various psychological, social and health related outcomes, especially, problematic ones (Kangro, 2011).

Like other attention and activity behaviours, researchers point to possible yet multifactorial causes of impulsivity. For example, it has been reported that as the brain develops in a foetus, it experiences complex and sensitive changes. If a pregnant woman smokes during this period, she can massively affect the foetus's brain chemistry, by predisposing the foetus to impulsivity (Deliz, 2008). A particular gene, 5HT2A102 which is known to be critical in the regulation of impulses by contributing to serotonin regulation, has also been implicated in Attention Deficit Hyperactive Disorder (ADHD), aggression and suicidal behaviours. People who possess two of such genes on paired chromosomes score higher on personality tests of impulsivity relative to those with one or no copies of this gene (Kreisman \& Straus, 2004). Werback (1995) has also shown that deficiencies in such vitamins as niacin, panthothenic acid, thiamine, and vitamins $B$ and $C$ could be associated with irritability and impulsivity. Further, Electroencephalograph (EEG) and Position Emission Tomography (PET) scans show that impulsive children have decreased blood flow, glucose utilisation and EEG activation (Woods \& Ploof, 1997). Impulsivity has also been shown to be caused by watching too much television, excessive sugar intake, and poor discipline. Inadequate mental stimulation, lack of attention and rejection all exacerbate signs of impulsivity (Deliz, 2008). 
Children diagnosed of impulsivity are at risk of school failure (Fredriksen et al., 2014); they have been associated with poor grades (DuPaul et al., 2016) and low academic achievements (Spinella \& Miley, 2003), relative to their peers without impulsivity. In her seminal study, Olasehinde (1991) reported that subjects with impulsivity were considerably more likely to have repeated a grade or dropped out of high school, compared to those without impulsivity, even after adjusting for social status, intelligence quotient, and learning disabilities. In the Special Attention Project (2011) conducted in Ghana, the researchers reported impulsivity as the main cause of school failure and subsequent drop-out among Ghanaian students. However, in efforts to enhance academic successes in Ghana, educational researchers have largely focused on such factors as school environment (e.g., Etsey, 2005), teaching and learning materials (Asikhia, 2010; Cooper \& Robinson, 2010) and parent's socio-economic status (Obese, 2019). Learner factors such as the learner's approach to cognitive task (technically referred to as cognitive style) appear to have been largely ignored.

Research (eg., Franco et al., 2016; Peckham \& Johnson, 2019) shows that impulsive behaviours can be reduced using behavioural training strategies. Whereas such strategies appear to have been extensively explored in the Western, Asia and the Oceania, there is a large paucity of research on the use of cognitive behavioural strategies in modifying impulsive behaviour among children in Africa, especially, Ghana. Owing to differences in cultural and socialisation processes, which inadvertently shapes individual thoughts and behaviours, it is difficult to conveniently import results of studies conducted elsewhere for policy formulation and decision making in Ghana without any ecological test. Herein, the researchers attempted to reduce children's impulsive problem-solving tendencies using the cognitive modelling strategy. This strategy was chosen because it has been shown to be effective in children (see Nwamuo, 2010). The chief objectives of the study were to: (1) examine the efficacy of a cognitive modelling procedure in the reduction of children's impulsive problem-solving approaches (2) assess the sustainability of the cognitive modelling procedure after the cessation of treatment (3) assess the relationship between a reduction in children's impulsivity and their performance in English Language and Mathematics. Three hypotheses were raised and tested in the study based on the objectives: (i) There is no significant effect of cognitive modelling in the reduction of impulsivity among children (ii) there is no sustainable effect of cognitive modelling in the reduction of children's impulsivity after the cessation of treatment (iii) there is no significant relationship between a reduction in children's impulsivity and their performance in English language and mathematics.

\section{Cognitive Modelling Training and Impulsivity}

Modelling is a form of observational learning in which adults or peers demonstrate appropriate problem-solving strategies to a client. It is a behavioural technique used by clinicians and psychologists alike, to modify the feelings and behaviours of a client by influencing the client's pattern of thought. Bandura (1969) pioneered the use of modelling to treat phobias, especially for fear of animals such as snakes and dogs. The theory is useful in explaining how individuals acquire new behaviours by observing other people perform such behaviours. Many studies have shown the effectiveness of modelling in behaviour modification. For example, Gorrell (1993) randomly assigned undergraduate students to one of four experimental groups and provided them with two types of instructional procedures (direct instruction and cognitive modelling) and two types of rule presentation (explicit and implicit) of classroom management procedures. When presented with hypothetical classroom management problems, subjects were expected to apply the behaviour analysis rules they learned. Results showed significant effects favouring cognitive modelling and implicit rule presentation on both problemsolving measures and self-efficacy measure. Odoemelam (1994) also used peer modelling to reduce behaviour problem and increase selfconcept of her pupils. The treatment was effective on children with minor, mild and moderate behaviour problems. Further, Nwamuo (2010) employed cognitive modelling to modify impulsive behaviour of some primary school children. Results were that modelling was effective in reducing the impulsiveness of participants, and improving their academic performance, with the modified behaviour being sustained a month after the withdrawal of intervention. Further, Nkrumah, Olawuyi, and Torto-Seidu (2015) used cognitive modelling to train impulsive children to delay responses and improve their performance on the Matching Familiar Figures Test (MFFT-20) cognitive task. In the present study, the modelling technique employed, required an instructor (described as a model) to systematically and carefully reveal his or her thoughts and reasoning during the execution of a task. The learner is trained and encouraged to use similar thinking processes. Such modelling procedures have the potential for strengthening applicable rules by providing additional personal associations that make the rules more relevant to the learner, by tying the examples presented in training to later problems, and by emphasising similarities between training and transfer tasks (Gorrell, 1993). According to Pedersen and Liu (2002) externalisation of these normally internal cognitive events allow students to see how an expert uses domain specific knowledge and a range of problem-solving strategies to perform tasks within a given context. In the study by Pedersen and Liu (2002) they used hypermedia program that offered modelling of pertinent strategies as students were engaged in problemsolving situations. While the classroom teacher could also model his or her cognitive processes for the class, presentation of this modelling through hypermedia had the distinct advantage of adding some excitement to the learning process. The result was that the cognitive modelling offered by the expert tool not only led experimental students to apply effective problem-solving strategies to their work, but in addition, it impacted the quality of their reasoning and their ability to present it in a convincing rationale for their solutions. In addition to improving certain kinds of academic performance, cognitive modelling increases the learner's expectations of success or perceived self-efficacy in performing similar procedures because the higher one's self-efficacy beliefs, the greater one's persistence and effort in attempting to learn new skills, acquire new knowledge, or solve problems (Bandura, 1977, 1982).

\section{Impulsive Behaviour Modification and Academic Performance}

During childhood, children are expected to develop cognitive, behavioural and social skills that are essential for school success as well as later adult living. Children need to learn such skills for effective communication with their peers as well as adults; they need to learn how to pay attention in various situations and to follow rules. In order to achieve these skills, cognitive constructs such as inhibiting impulsive behaviour, self-regulation in which immediate gratification is delayed, responding to tasks in a manner that exhibits planning and problem solving, are essential (Barkley, 1997). Therefore, impulsive children who are usually hyperactive and have attentional capacity and impulse 
control difficulties, are bound to, among others, have problems with learning and achievement. Lower class and "culturally deprived" children tend to be impulsive (Kagan, 1966a), and the inferior intellectual performance displayed by such children could be a result of an impulsive attitude, in addition to deficits in cognitive resources. Although impulsivity is not the sole cause of errors, a child who consistently attacks a problem with impulsive approach may experience repeated failure (Olasehinde, 1991). Problem solving ability and solving problems have usually been the way to test performance in education and the most frequent areas of performance target has been in English and Mathematics (Ammer, 1983; Ashori \& Jalil-Abkenar, 2015; Cameron \& Robinson, 1980; Kano, Ayana, \& Chali, 2017; Nwamuo, 2010; Olasehinde, 1986; Schunk, 1981). In the present study, English language and Mathematics were employed because the educational objective of basic education in Ghana is to train learners in numeracy and accuracy (herein described as English and Mathematics).

Impulsive individuals by their nature suffer greatly on standardized testing and classroom assignments, and in many situations, the MFFT performance has been found to correlate reasonably well with academic achievement (Haskins \& McKinney, 1976). In a study to indicate strategic and efficient performance on a problem-solving behaviour of children in grades two, four, and six in a pattern matching (PM) task, it was confirmed that reflectives were more strategic than impulsives (Cameron, 1984). A task-analysis assessment conducted identified the sources of inefficient PM performance to include failure to retain instructions, failure to formulate appropriate solution strategy, and failure to consistently implement a good strategy. The latter two were related to conceptual tempo in the sense that children who were more impulsive tended to report lower quality solution strategies, and if they formulated effective solution strategies, they did not consistently implement those strategies. Not only was Cameron and Robinson's (1980) study successful, but the subjects achieved high accuracy in Mathematics which also generalised to other non-trained areas in oral reading. Most of the aforementioned studies reported improvement in academic performance of children (following impulsive behaviour modification) both with classroom impulsivity as well as clinical cases. For Lawry et al. (1983), the question remains as to what extent processing differences between the two dimensions (reflectivity/impulsivity) influence performance across a variety of problem-solving contexts. The conditions under which speed and/or accuracy differences emerge have not been specified fully. For example, it is not known whether quick response is generally indicative of impulsive performance in the majority of problem-solving tasks or only those that require visual comparisons. Similarly, it is not clear if slow response is generally characteristic of reflective performance across problem-solving tasks that vary in difficulty and amount of analytic reasoning involved. The importance of any group differences must be assessed over the full range of performance observed within the groups. Data suggests that modification of the decision strategy of the child may have subsequent effects on his problem-solving ability (Kagan, Pearson, \& Welch, 1966b; Yando \& Kagan, 1968), and finally of his academic achievement. Herein, the researchers assumed that a reduction in children's impulsivity would have a positive impact on their academic achievements in English and mathematics.

\section{METHODS}

\section{Subjects}

Ninety-three (47 males and 46 females) children from the Tamale Cluster of Schools in Ghana, took part in the study. The children were aged 9 to 11 years, with an average age of 10 . They were purposively selected as subjects based on their scores on the behavioural rating scales employed in the study.

\section{Instruments}

The instruments for the study were grouped into three, namely; Screening tools, Training Package and Assessment tools. The screening tools were used for identifying the impulsive children from the nonimpulsive ones. The training package was used as intervention in the experimental groups, aimed at reducing subjects' impulsive tendencies. The assessment tools consisted of tests employed in assessing the entry behaviour of the research subjects, then tests used in ascertaining whether impulsivity had been reduced (or otherwise) after intervention and finally test used to check whether a reduction (or otherwise) in impulsivity has any effect on pupil's performance in English language and Mathematics. The instruments are briefly described below:

\section{Screening tools}

- National Initiative for Children's Healthcare QualityVanderbilt Assessment Scale-Teacher Informant (NICHQ-VAS-TI)this is a detailed measure that contains impulsivity characteristics that children usually present at school. It was completed by teachers for each pupil in their class.

- Checklist on Impulsiveness for Parents (CIFP) - The CIFP was used by parents to measure pupils' behaviours in their homes. The scale consists of items that correspond to various characteristics of impulsivity which children display in their homes.

- Impulsive Related Questionnaire for Children (IRQC)- This is a self-report questionnaire that elicited information from the pupils on their own behavioural characteristics. The pupils ticked in the column that they felt matched their personal descriptions.

\section{Treatment package}

- Training Package in Cognitive Modelling- this was a training programme carefully designed by educational psychologists and instructors to help pupils adopt reflective approaches in problem solving. The training procedure engaged pupils on observation skills and in reflective problem-solving skills in which they had to make careful comparison among and between objects based on properties (such as weight) and physical features (such as colour, shape, size); grouping and sorting similar objects and identifying similarities and differences among objects based on common characteristics; sequencing events; putting together parts of a whole, etc. Close observation to give as detailed a description of objects as possible was emphasized. They were shown videos of impulsive children and the behaviours they show such as blurting out incorrect answers before being called, finishing exercises quickly but with many errors, making careless mistakes, impatience in having to wait their turn etc, and a discussion was held on the causes and effects of such behaviours based on the scenarios. They were then asked to describe some other distracting behaviours (eg. looking out of the window, leaving their seats, playing while others were working, not following instructions as they were given etc.). To break these behaviour chains, they were 
encouraged to listen attentively in class as they could be called by the teacher at any time to respond to questions.

\section{Assessment tools}

- Matching Familiar Figures Test-20 (MFFT-20)- The MFFT20 consists of many items each of which was similar to a standard figure. For each figure called the standard, there were five other figures called variants. Although the five variants were similar to the standard, only one was exactly the same as the standard. The task of the pupil was to select from among the variants the one figure that matched the standard. Three versions of the MFFT-20 (sixty items) were used in the study and they were grouped as MFFT-20 (I), MFFT-20 (II) and MFFT-20 (III) for use in pretest, posttest and delayed posttest measures respectively.

- Academic Performance Tests in English Language and Mathematics- These were two sets of teacher-made performance tests in each of the subjects (English and Mathematics) that were used to test problem solving skills of all pupils. It must be noted that all the instruments employed here underwent standardisation procedures of face and content validation.

\section{Design}

The Solomon-Four Group experimental design was employed. Subjects were randomly divided into four groups of A, B, C and D. Table 1 shows the assignment procedures.

\section{Procedure for Data Collection}

The initial stage of data collection involved the filling of the NACHQ-VAS-TI by the class teachers in the school. The parents also completed the CIFP on behalf of their wards, and finally the children filled the IRQFP by themselves. Since most of the parents could neither read nor write, they were assisted by trained research assistants who translated the English statements on the rating scale into their local dialects (Dagbani, a native language of Ghana, Africa), then the parent told the assistant the option that they felt related to their ward. Likewise, the children were assisted by the research assistants in filling their rating scales, using the same procedure as used with their parents. Scores on the three ratings scales; NICHQ, CIFP and IRQFP were analysed and pupils who got the required scores on all the three instruments were deemed impulsive and they constituted the study's sample. Ninety-three pupils out of the 539 pupils who were screened were described as impulsive and they formed the sample for the study. The ninety-three subjects were randomly posted into one of the four groups (see Table 1) adopted in the study. As shown in Table 1, subjects in Group 1 were pretested, given intervention and then post-tested. Group 2 were pretested but received no intervention and then posttested. Group 3 subjects received no pre-test but were given intervention and then post-tested, and finally those in Group 4 were not pretested, did not receive intervention but were posted. All the four groups were also given performance test in English and Mathematics, after post-test. The control groups were given placebo in creative arts exercises and drawing whereas the experimental groups received training in cognitive modelling during the intervention period. The intervention procedure lasted for eight weeks (Nkrumah et al., 2017), three days in a week. The contact periods for both the experimental and control groups were one hour a week, three times in a week.
Table 1. Solomon four group distribution

Key

\begin{tabular}{cccc}
\hline Test group & Pre-test & Treatment & Post-test \\
\hline 1 & $\mathrm{O}_{1}$ & $\mathrm{X}$ & $\mathrm{O}_{2}$ \\
\hline 2 & $\mathrm{O}_{1}$ & ----- & $\mathrm{O}_{2}$ \\
\hline 3 & ----- & $\mathrm{X}$ & $\mathrm{O}_{2}$ \\
\hline 4 & ----- & ---- & $\mathrm{O}_{2}$ \\
\hline
\end{tabular}

$\mathrm{O}_{1}$-Pretest, $\mathrm{O}_{2}$-Posttest, $\mathrm{X}$-intervention

----- no pretest/no intervention

\section{RESULTS AND DISCUSSION}

The results are presented in order of the hypotheses that were raised in the study. The analyses were done in two-fold; reaction time and accuracy scores. A reduction in impulsivity is interpreted as increased reaction time and increased accuracy scores.

Ho1:There is no significant effect of cognitive modelling on the problemsolving abilities of impulsive children.

$H_{0}$ 1: There is no significant sustainable effect of cognitive modelling on the problem-solving abilities of impulsive children.

A two-way between groups MANOVA was used to test the effect of cognitive modelling training on the problem-solving abilities of the pupils. Problem-solving ability in this study was measured with the MFFT-20 (accuracy score and response time). Thus, there were two dependent variables. Four groups were involved in this strategy. Two of the groups were pre-tested, while two were not pre-tested. The two independent factors in this analysis were experimental treatment and whether pre-test was administered or not. Table 2 illustrates the means and standard deviation for the treatment and pre-test factors.

Table 2 shows a higher MFFT accuracy mean score for the pretested experimental group compared with the non-pretested experimental group. It is possible that pre-testing influenced the results because, the pretested control group had a lower MFFT accuracy mean score than the no-pretested control group. However, pretesting did not gain an advantage for the control group. The results for response time indicates that for the experimental groups, the means for the pretest group (12.67) and the nonpre-test group (10.39) were significantly different (Mean diff $=2.28, \mathrm{p}=.009$ ), but the means for the control groups did not differ significantly between the pretest (11.08) and nonpretested (12.19) groups (Mean diff $=1.105, \mathrm{p}=.145$ ). Thus, the pretest effect was only evident in the experimental groups, with the pretest group having a higher response time than the non-pretest group. The Box's test of equality of covariance indicated that the covariances were equal across the groups in the test. The MANOVA multivariate results showed that there was no significant main effect for treatment [Wilk's $\lambda=.999, \mathrm{~F}(2,88)=.065, \mathrm{p}=.937, \eta 2 \mathrm{p}=.001]$ and pre-test [Wilk's $\lambda=$ $.967, \mathrm{~F}(2,88)=.1 .493, \mathrm{p}=.230, \eta 2 \mathrm{p}=.033]$. There was however, a significant main interaction effect of treatment and pre-test [Wilk's $\lambda=$ $.843, \mathrm{~F}(2,88)=.8 .186, \mathrm{p}=.001, \eta 2 \mathrm{p}=.157]$. The univariate between subjects' tests were examined to see which of the independent variables had the significant interaction effect. The results showed that there was significant interaction effects for both MFFT accuracy rate $[\mathrm{F}(1,89)=$ 84.703, $\mathrm{p}<.001, \eta 2 \mathrm{p}=.151]$ and response time $[\mathrm{F}(1,89=64.906, \mathrm{p}=$ $.004, \eta 2 \mathrm{p}=.091]$. This indicated that the pre-test had significant effect on the post-test scores. The simple effects test was therefore performed for the pre-tested groups and non-pretested groups to get the exact 
Table 2. Descriptive statistics for MFFT 2 and RTIME 2 for experimental and pre-test factors

\begin{tabular}{|c|c|c|c|c|c|}
\hline & Experimental or Control & Pre-test or no pre-test & Mean & Std. Deviation & $\mathbf{N}$ \\
\hline \multirow{8}{*}{$\begin{array}{l}\text { MFFT } 2 \\
\text { SCORE }\end{array}$} & \multirow{3}{*}{ Exp'al } & Pretest & 9.56 & 1.688 & 18 \\
\hline & & No pretest & 6.78 & 2.110 & 23 \\
\hline & & Total & 8.00 & 2.366 & 41 \\
\hline & \multirow{3}{*}{ Control } & Pretest & 7.80 & 2.872 & 25 \\
\hline & & No pretest & 8.89 & 2.242 & 27 \\
\hline & & Total & 8.37 & 2.597 & 52 \\
\hline & \multirow[t]{2}{*}{ Total } & No pretest & 7.92 & 2.406 & 50 \\
\hline & & Total & 8.20 & 2.492 & 93 \\
\hline \multirow{8}{*}{ RTIME 2} & \multirow{3}{*}{ Exp'al } & Pretest & 12.67 & 1.910 & 18 \\
\hline & & No pretest & 10.39 & 3.230 & 23 \\
\hline & & Total & 11.39 & 2.932 & 41 \\
\hline & \multirow{2}{*}{ Control } & Pretest & 11.08 & 2.499 & 25 \\
\hline & & Total & 11.65 & 2.714 & 52 \\
\hline & \multirow{3}{*}{ Total } & Pretest & 11.74 & 2.381 & 43 \\
\hline & & No pretest & 11.36 & 3.128 & 50 \\
\hline & & Total & 11.54 & 2.800 & 93 \\
\hline
\end{tabular}

Table 3. Pairwise comparisons of treatment and pre-test/post-test MFFT 2 accuracy mean scores

\begin{tabular}{|c|c|c|c|c|c|c|c|}
\hline \multirow{2}{*}{$\begin{array}{l}\text { Pretest or No } \\
\text { Pretest }\end{array}$} & \multirow{2}{*}{$\begin{array}{c}\text { (I) Exp'tal or } \\
\text { Control }\end{array}$} & \multirow{2}{*}{$\begin{array}{c}\text { (J) Exp'tal or } \\
\text { Control }\end{array}$} & \multirow{2}{*}{$\begin{array}{c}(\mathrm{I}-\mathrm{J}) \\
\text { Mean Diff }\end{array}$} & \multirow{2}{*}{ Std. Error } & \multirow{2}{*}{ Sig. ${ }^{b}$} & \multicolumn{2}{|c|}{ 95\% Confidence Interval for Diff ${ }^{b}$} \\
\hline & & & & & & Lower Bound & Upper Bound \\
\hline \multirow{2}{*}{ Pretest } & Exp'tal & Control & $1.756^{*}$ & .714 & .016 & .337 & 3.175 \\
\hline & Control & Exp'tal & $-1.756^{*}$ & .714 & .016 & -3.175 & -.337 \\
\hline No & Exp'tal & Control & $-2.106^{*}$ & .656 & .002 & -3.409 & -.804 \\
\hline Pretest & Control & Exp'tal & $2.106^{*}$ & .656 & .002 & .804 & 3.409 \\
\hline
\end{tabular}

Dependent Variable: MFFT 2 SCORE:*.

The mean difference is significant at the .05 level. b. Adjustment for multiple comparisons: Sidak.

Table 4. Pairwise comparison for MFFT 2 accuracy

\begin{tabular}{|c|c|c|c|c|c|c|c|}
\hline \multirow{2}{*}{$\begin{array}{l}\text { Exp'tal or } \\
\text { Control }\end{array}$} & \multirow{2}{*}{$\begin{array}{c}\text { (I) Pretest } \\
\text { or no pretest }\end{array}$} & \multirow{2}{*}{$\begin{array}{l}\text { (J) Pretest or no } \\
\text { pretest }\end{array}$} & \multirow{2}{*}{$\begin{array}{c}\text { (I-J) } \\
\text { Mean Diff }\end{array}$} & \multirow{2}{*}{ Std. Error } & \multirow{2}{*}{ Sig. ${ }^{b}$} & \multicolumn{2}{|c|}{ 95\% Confidence Interval for Diff } \\
\hline & & & & & & Lower Bound & Upper Bound \\
\hline \multirow{2}{*}{ Exp'tal } & Pretest & No pretest & $2.773^{*}$ & .727 & .000 & 1.328 & 4.218 \\
\hline & No pretest & Pretest & $-2.773^{*}$ & .727 & .000 & -4.218 & -1.328 \\
\hline \multirow{2}{*}{ Control } & Pretest & No pretest & -1.089 & .641 & .093 & -2.363 & .185 \\
\hline & No pretest & Pretest & 1.089 & .641 & .093 & -.185 & 2.363 \\
\hline
\end{tabular}

Based on estimated marginal means

*. The mean difference is significant at the .05 level.

b. Adjustment for multiple comparisons: Sidak.

nature of the interaction effects for the MFFT accuracy rate and response time in Table 3.

The simple effects analysis in Table 3 indicates that there was a significant difference between the experimental and control group scores on accuracy rate for both pretest (Mean diff $=1.76, \mathrm{p}=.016)$ and non-pretested (Mean diff $=2.11, \mathrm{p}=.002$ ) groups. For the pre-tested groups, the mean accuracy score for the experimental group was higher than the control group, while the reverse was the case for the nonpretest groups. Thus, MFFT accuracy scores for the pretested groups had improved, while scores for the non-pretested groups had significantly reduced. Table 4 presents the comparison of mean differences between experimental and control groups with regard to pretest or non-pretest.

The results indicate a significant difference between the pretest group and the non-pretest group means on the MFFT accuracy for the experimental groups (Mean diff $=2.77, \mathrm{p}<.001$ ), but there was no significant difference for the control groups (Mean diff $=1.09, \mathrm{p}=.093$ ). The within group ANOVA test was conducted to test whether there were significant changes between the three measures (pretest, posttest and delayed posttest). The Mauchly's Test of Sphericity indicated that the variance of the difference between each pair of repeated measures of MFFT accuracy was approximately equal $[\mathrm{W}(2)=.928, \mathrm{p}=.223$ ]. The results of the within group ANOVA showed that both MFFT accuracy $\left[\mathrm{F}(2,82)=23.56, \mathrm{p}<.001, \eta^{2} \mathrm{p}=.365\right]$ and interaction effect $\left[\mathrm{F}(2,82)=6.759, \mathrm{p}=.002, \eta^{2} \mathrm{p}=.142\right]$ were significant. Pairwise comparison results (Table 4) showed that the pre-test accuracy score was significantly lower than both posttest (Mean diff $=2.75, \mathrm{p}<.001$ ) and delayed posttest (Mean diff $=2.68, \mathrm{p}<.001$ ). There was, however, no significant difference between the posttest and delayed post (Mean diff $=.076, \mathrm{p}=.998)$ as presented in Table 5 .

Further, within-group ANOVA analysis results showed MFFT accuracy differences between the pretest and the posttest (Mean diff = $4.22, \mathrm{p}<.001$ ), and delayed post (Mean diff $=4.11, \mathrm{p}<.001$ ), but no difference between the posttest and the delayed posttest response times, indicating that for the experimental group that received pretest, there was priming for the posttest. There was however no significant difference between any of the pairs of means in the control group. This implies that the cognitive modelling strategy has been effective in 
Table 5. Pairwise comparison of pre, post and delayed post MFFT

\begin{tabular}{|c|c|c|c|c|c|c|}
\hline \multirow{2}{*}{ (I) MFFT } & \multirow{2}{*}{$\begin{array}{c}(\mathrm{J}) \\
\text { MFFT }\end{array}$} & \multirow{2}{*}{$\begin{array}{c}\text { (I-J) } \\
\text { Mean Diff }\end{array}$} & \multirow{2}{*}{ Std. Error } & \multirow{2}{*}{ Sig. ${ }^{b}$} & \multicolumn{2}{|c|}{ 95\% Confidence Interval for Diff $b$} \\
\hline & & & & & Lower Bound & Upper Bound \\
\hline \multirow{2}{*}{ Pretest } & Post test & $-2.751^{*}$ & .403 & .000 & -3.753 & -1.749 \\
\hline & Delayed & $-2.676^{*}$ & .509 & .000 & -3.942 & -1.409 \\
\hline \multirow{2}{*}{ Post test } & Pretest & $2.751^{*}$ & .403 & .000 & 1.749 & 3.753 \\
\hline & Delayed & .076 & .452 & .998 & -1.050 & 1.201 \\
\hline \multirow{2}{*}{ Delayed } & Pretest & $2.676^{*}$ & .509 & .000 & 1.409 & 3.942 \\
\hline & Post test & -.076 & .452 & .998 & -1.201 & 1.050 \\
\hline
\end{tabular}

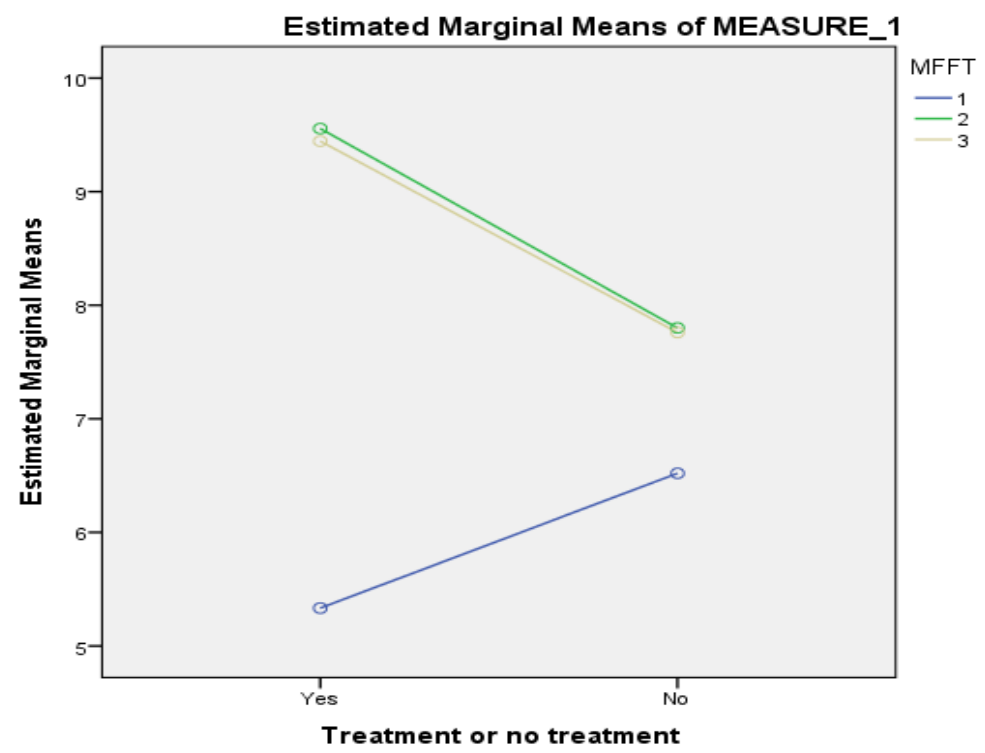

MFFT $1=$ Pretest, MFFT $=$ Post test, MFFT 3 = Delayed Post test

Figure 2. Means plot for MFFT accuracy

Table 6. Within-subjects' effects-pre, post, delayed post for RTime

\begin{tabular}{|c|c|c|c|c|c|c|c|}
\hline & Irce & Type III Sum of Squares & Df & Mean Square & $\mathbf{F}$ & Sig. & $\eta 2 p$ \\
\hline \multirow{4}{*}{ RTIME } & Sphericity Assumed & 922.139 & 2 & 461.070 & 74.056 & .000 & .644 \\
\hline & Greenhouse-Geisser & 922.139 & 1.930 & 477.836 & 74.056 & .000 & .644 \\
\hline & Huynh-Feldt & 922.139 & 2.000 & 461.070 & 74.056 & .000 & .644 \\
\hline & Lower-bound & 922.139 & 1.000 & 922.139 & 74.056 & .000 & .644 \\
\hline \multirow{3}{*}{ RTIME * Treatment } & Sphericity Assumed & 37.488 & 2 & 18.744 & 3.011 & .055 & .068 \\
\hline & Greenhouse-Geisser & 37.488 & 1.930 & 19.426 & 3.011 & .057 & .068 \\
\hline & Lower-bound & 37.488 & 1.000 & 37.488 & 3.011 & .090 & .068 \\
\hline \multirow{4}{*}{ Error (RTIME) } & Sphericity Assumed & 510.527 & 82 & 6.226 & & & \\
\hline & Greenhouse-Geisser & 510.527 & 79.123 & 6.452 & & & \\
\hline & Huynh-Feldt & 510.527 & 82.000 & 6.226 & & & \\
\hline & Lower-bound & 510.527 & 41.000 & 12.452 & & & \\
\hline
\end{tabular}

improving problem solving strategy of the subjects. Figure 2 presents a pictorial view of mean scores of pre, post and delayed post MFFT accuracy scores for the experimental and control groups.

Figure 2 suggests that the difference between the pretest and the posttest accuracy score was sustained to the delayed posttest. Though the between-subject effects showed no significant overall treatment effect, the significant interaction effect suggests that the within-group effect differs between the experimental and control groups. The pairwise comparisons also show that there was no significant difference in the pretest scores between the experimental and control groups (Mean diff $=1.19, \mathrm{p}=.145$ ). This suggests that the two experimental conditions had equivalent baseline. For the posttest, however, there was a significant difference between the experimental and control groups (Mean diff $=1.76, \mathrm{p}=.026$ ), with the mean accuracy rate for the experimental group being higher than that of the control. This effect was sustained to the delayed post. The within-group ANOVA analysis was again used to test whether the mean scores of the response time for pretest, posttest and delayed posttest were significantly different. The Mauchly's Test of Sphericity was first measured for response time. And it showed there was equality of variance within the three measures [W $=.964, \mathrm{p}=.477]$. The statistics for the sphericity assumed was therefore reported for the between subjects' effects. The within-subjects effect for response time is presented in Table 6. 
Table 7. Pairwise Comparison of 3 of Rtime

\begin{tabular}{|c|c|c|c|c|c|c|}
\hline \multirow{2}{*}{ (I) RTIME } & \multirow{2}{*}{ (J) RTIME } & \multirow{2}{*}{$\begin{array}{c}(\mathrm{I}-\mathrm{J}) \\
\text { Mean Diff }\end{array}$} & \multirow{2}{*}{ Std. Error } & \multirow{2}{*}{ Sig. ${ }^{b}$} & \multicolumn{2}{|c|}{ 95\% Confidence Interval for Diff b } \\
\hline & & & & & Lower Bound & Upper Bound \\
\hline \multirow{2}{*}{ Pretest } & Posttest & $-3.609^{*}$ & .491 & .000 & -4.830 & -2.387 \\
\hline & Delayed Posttest & $-6.629^{*}$ & .569 & .000 & -8.045 & -5.213 \\
\hline Posttest & Delayed Posttest & $-3.020^{*}$ & .573 & .000 & -4.446 & -1.594 \\
\hline \multirow{2}{*}{ Delayed Posttest } & Pretest & $6.629^{*}$ & .569 & .000 & 5.213 & 8.045 \\
\hline & Posttes & $3.020^{*}$ & .573 & .000 & 1.594 & 4.446 \\
\hline
\end{tabular}

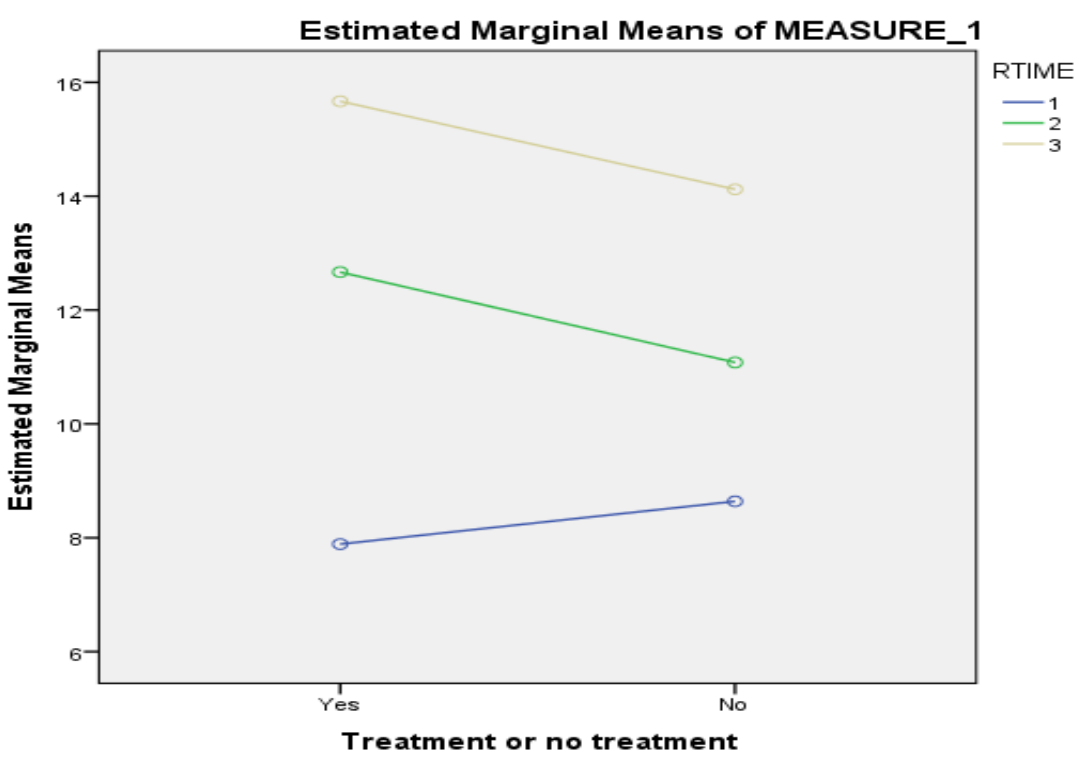

Figure 3. Means plot on RTimes for experimental and control groups

The results from Table 6 show significant differences exist in response time within the experimental and control groups $[\mathrm{F}(2,82)=$ 74.06, $\left.\mathrm{p}<.001, \eta^{2} \mathrm{p}=.644\right]$. There was however, no interaction effect of treatment and response time measures $[\mathrm{F}(2,82)=3.01, \mathrm{p}=.056, \eta 2 \mathrm{p}=$ $.068]$.

The post hoc analysis then was done, following significant within subject effect to find out which of the measures significantly differ. Comparison between the three measures of Response Time is presented in Table 7.

The results show that the posttest response time was significantly lower than that of the pretest (mean diff $=3.61, \mathrm{p}<.001$ ), and the delayed posttest response time was further lower than the pretest (mean $\operatorname{diff}=6.63, \mathrm{p}<.001)$ ). Again, the response time for the delayed post was significantly lower than that of the posttest (mean diff $=3.02, \mathrm{p}<.001$ ). Given that there was no significant interaction effect of treatment and time measures, this means the results indicated here were similar for both experimental and control groups. All the three measures of pretest, posttest and delayed posttest for response time were significant. The results further indicated that the baseline measure (pretest) response time for the experimental and control groups were not significantly different $($ Mean diff $=.751, \mathrm{p}=.323$ ). There was, however, a significant difference between the experimental and control groups at the posttest (Mean diff $=1.59, \mathrm{p}=.029)$, but no significant difference was observed with regard to the delayed posttest (Mean diff $=1.54, \mathrm{p}=.100$ ). The means plot of RTime for experimental and control groups is presented in Figure 3.

The experimental treatment was effective in increasing the response time of the pupils in the study at post-test measures. There was also an increase in the difference between the post-test and the delayed post-test. The implication here is that the cognitive modelling strategy has been effective in improving problem solving ability of the pupils. The null hypothesis is therefore rejected. The results obtained here are consistent with some other studies that used modelling in modifying the impulsive characteristics of their research subjects (eg., Herman, 1982; Nkrumah, 2013; Nwamuo, 2010; Olasehinde, 1992). For example, Schunk (1981) provided children deficient in division skills with either cognitive modelling of division operations or didactic instruction, along with practice opportunities, over a number of sessions. During cognitive modelling, the children observed an adult model verbalize operations while solving problems. Children who received training in cognitive modelling solved more division problems correctly on post-test, although both treatments enhanced self-efficacy on division operations equally. Nwamuo (2010) also modified the disruptive behaviours of some primary school children using cognitive modelling. Results of her study showed that modelling was effective in reducing impulsive behaviour characteristics of her subjects after intervention. Further, Nkrumah (2013) employed modelling to train impulsive children to delay responses and increase their accuracy scores on the MFFT-20. Results showed improved accuracy scores and delayed response in the experimental group relative to the control group. In the original modelling experiment conducted by Bandura (1981), the research subjects were children. It therefore seems to suggest that the technique is more effective when employed with children, as wildly reiterated by Odoemelam (1994). However, some other studies have modified young adults (and teenagers) disruptive behaviours using modelling. Olasehinde (1992) for example, trained some impulsive senior secondary school students on how to approach 
Table 8. Multivariate tests effect of cognitive modelling on performance

\begin{tabular}{|c|c|c|c|c|c|c|c|}
\hline & Effect & Value & $\mathbf{F}$ & Hypothesis df & Error df & Sig. & $\eta 2 \mathrm{p}$ \\
\hline \multirow{4}{*}{ Exp'tal } & Pillai's Trace & .250 & $14.633^{\mathrm{b}}$ & 2.000 & 88.000 & .000 & .250 \\
\hline & Wilks' Lambda & .750 & $14.633^{\mathrm{b}}$ & 2.000 & 88.000 & .000 & .250 \\
\hline & Hotelling's Trace & .333 & $14.633^{\mathrm{b}}$ & 2.000 & 88.000 & .000 & .250 \\
\hline & Roy's Largest Root & .333 & $14.633^{\mathrm{b}}$ & 2.000 & 88.000 & .000 & .250 \\
\hline \multirow{3}{*}{ Pre-test } & Pillai's Trace & .297 & $18.627^{\mathrm{b}}$ & 2.000 & 88.000 & .000 & .297 \\
\hline & Wilks' Lambda & .703 & $18.627^{\mathrm{b}}$ & 2.000 & 88.000 & .000 & .297 \\
\hline & Roy's Largest Root & .423 & $18.627^{\mathrm{b}}$ & 2.000 & 88.000 & .000 & .297 \\
\hline \multirow{4}{*}{ Exp'tal * Pretest } & Pillai's Trace & .113 & $5.616^{\mathrm{b}}$ & 2.000 & 88.000 & .005 & .113 \\
\hline & Wilks' Lambda & .887 & $5.616^{\mathrm{b}}$ & 2.000 & 88.000 & .005 & .113 \\
\hline & Hotelling's Trace & .128 & $5.616^{\mathrm{b}}$ & 2.000 & 88.000 & .005 & .113 \\
\hline & Roy's Largest Root & .128 & $5.616^{\mathrm{b}}$ & 2.000 & 88.000 & .005 & .113 \\
\hline
\end{tabular}

Table 9. Test of between-subjects' effects

\begin{tabular}{|c|c|c|c|c|c|c|c|}
\hline Source & Dependent Variable & $\begin{array}{c}\text { Type III Sum of } \\
\text { Squares } \\
\end{array}$ & df & Mean Square & $\mathbf{F}$ & Sig. & $\eta 2 \mathrm{p}$ \\
\hline \multirow{2}{*}{ Treatment } & ENG 2 SCORE & 548.011 & 1 & 548.011 & 1.865 & .176 & .021 \\
\hline & MATH 2 SCORE & 5792.334 & 1 & 5792.334 & 26.291 & .000 & .228 \\
\hline \multirow{2}{*}{ Pre-test } & ENG 2 SCORE & 928.475 & 1 & 928.475 & 3.159 & .079 & .034 \\
\hline & MATH 2 SCORE & 7153.929 & 1 & 7153.929 & 32.471 & .000 & .267 \\
\hline \multirow{2}{*}{ Experiment $*$ Pre-test } & ENG 2 SCORE & 186.651 & 1 & 186.651 & .635 & .428 & .007 \\
\hline & MATH 2 SCORE & 2246.204 & 1 & 2246.204 & 10.195 & .002 & .103 \\
\hline \multirow{2}{*}{ Error } & ENG 2 SCORE & 26157.166 & 89 & 293.901 & & & \\
\hline & MATH 2 SCORE & 19608.271 & 89 & 220.318 & & & \\
\hline \multirow{2}{*}{ Total } & ENG 2 SCORE & 385325.000 & 93 & & & & \\
\hline & MATH2 SCORE & 333819.000 & 93 & & & & \\
\hline
\end{tabular}

cognitive task reflectively. The results of her studies showed that there was an increased performance of the experimental group as against the control group at post-test measures. Gorrell (1993) also improved the classroom management skills of some undergraduate students using cognitive modelling. Such studies add to the literature to suggest that the modelling technique is effective for both adult and children populations, and also for assisting in resolving varied behavioural problems. In the present study and some others (Nkrumah, 2013; Nwamuo, 2010; Olasehinde, 1992; Schunck, 1981) the technique was used to assist impulsive subjects to approach cognitive problem-solving task reflectively and they reported positive results. Some other researchers employed modelling to increase the self-efficacy (Odoelemam, 1994) and the self-concept (Gorrell, 1993) of their research subjects and they also reported that the technique was effective. In effect, the modelling technique seems to be efficient not only with cognitive problem-solving abilities, but also other areas of psychological traits as indicated above. In addition, the technique appears effective irrespective of ecology. For example, it has been shown to achieve positive results in studies conducted in the Western countries (Schunk \& Hanson, 1985), Oceania (Herman, 1982) and currently in Africa (Nkrumah, 2013; Nwamuo, 2010; Odoelemam, 1994).

\section{Hypothesis 3}

There is no significant effect of cognitive modelling on impulsive pupils' performance in Mathematics and English.

From descriptive statistics on English and Mathematics tests, the results for the English test showed that the pre-test scores for both experimental and control groups were lower than the non-pretested groups. In terms of performance the groups that were not pretested scored better than those who were. The same trend was observed in the
Mathematics scores. The two-way MANOVA test was conducted to find out whether the observed differences were significant. The Box's test of equality of covariance indicated that the covariances were not equal across groups. The Pillai's Trace statistics were therefore reported in Table 8.

The multivariate test in Table 8 showed significant effects for the experimental $[\mathrm{F}(2,88)=14.63, \mathrm{p}<.001, \eta 2 \mathrm{p}=.250]$, pretest condition $[\mathrm{F}(2,88)=18.63, \mathrm{p}<.001, \eta 2 \mathrm{p}=.297]$ as well as the interaction effect $[F(2,88)=5.62, p=.005, \eta 2 p=.113]$. The between subjects' effects for the dependent variables (English and Mathematics) were analysed. The Levene's test showed variance for the subjects was not equal. Tests for between-subjects' effects for English and Mathematics performance are displayed in Table 9.

The results of the between-subjects effects in Table 10 showed significant effect for experimental condition $[\mathrm{F}(2,88)=14.63$, $\mathrm{p}<.001$, $\eta 2 \mathrm{p}=.250]$, pre-test condition $[\mathrm{F}(2,88)=18.63, \mathrm{p}<.001, \eta 2 \mathrm{p}=.297]$ and interaction on only Mathematics. There was no effect on English test score. The post hoc analysis was therefore done for Mathematics performance in Table 10.

The pairwise comparison for Mathematics in Table 10 showed significant difference between the experimental group and control group (Mean diff $=15, \mathrm{p}<.001)$.

Comparison between pretest and non-pretest groups also showed significant difference between the two groups (Mean diff $=17.75, \mathrm{p}<$ .001). The results therefore demonstrated that the treatment had an effect on both pretest and non-pretest groups. However, the nonpretest group performed significantly higher than the pretest group. It is obvious in terms of problem-solving abilities that the groups were not equal, and the pre-test had no priming effect. The null hypothesis 
Table 10. Pairwise comparisons between experimental and control groups

\begin{tabular}{|c|c|c|c|c|c|c|c|}
\hline \multirow{2}{*}{ Dep Variable } & \multirow{2}{*}{$\begin{array}{c}\text { (I) } \\
\text { Exp'tal or Control }\end{array}$} & \multirow{2}{*}{$\begin{array}{l}\text { (J) Exp'tal or } \\
\text { Control }\end{array}$} & \multirow{2}{*}{$\begin{array}{c}\text { Mean Diff } \\
(\mathrm{I}-\mathrm{J})\end{array}$} & \multirow{2}{*}{ Std. Error } & \multirow{2}{*}{ Sig. ${ }^{b}$} & \multicolumn{2}{|c|}{ 95\% Confidence Interval for Diff ${ }^{b}$} \\
\hline & & & & & & Lower Bound & Upper Bound \\
\hline \multirow{2}{*}{ ENG 2 SCORE } & Exp'tal & Control & 4.911 & 3.597 & .176 & -2.235 & 12.058 \\
\hline & Control & Exp'tal & -4.911 & 3.597 & .176 & -12.058 & 2.235 \\
\hline \multirow{2}{*}{ MATH 2 SCORE } & Exp'tal & Control & $15.968^{*}$ & 3.114 & .000 & 9.780 & 22.155 \\
\hline & Control & Exp'tal & $-15.968^{*}$ & 3.114 & .000 & -22.155 & -9.780 \\
\hline
\end{tabular}

is therefore accepted. Studies on behaviour modification that tested the impact of the training strategies on students' performance have usually used English and Mathematics. In the present study, the researchers tested the efficacy of the modelling therapy on pupils' performance in Mathematics and English. The study found out that modelling had a positive impact on Mathematics but not in English. Schunk (1981) and Schunk and Hanson (1985) for example provided children deficient in division skills with either cognitive modelling of division operations (using adult models) and children deficient in subtraction skills with peer cognitive modelling. Children who received cognitive modelling both with adult and peer models, solved more division and subtraction problems correctly on the posttest, and also demonstrated enhanced self-efficacy in Mathematics problem solving. Herman (1982) also used cognitive modelling to improve Mathematics, reading and spelling performance of some impulsive subjects. None of the studies reviewed so far attempted to find out whether impulsive behaviour modification has impact on the problem-solving abilities of impulsive children in Mathematics better than in English or vice versa. Although there were no discrete hypotheses raised for the two subjects, the analyses show that there was improvement in subjects performance in Mathematics better than in English. Superficially, it is assumed that reflective processes are more engaging in Mathematics than in English. In Mathematics, for example, problems of addition that require carry overs demand grave impulse control (even when the child knows the correct approach) so that the child does not miss out on the "remainders". Also, in Mathematics, there are sometimes more than one way of approaching a problem, in such cases, the child has to think through the easiest approach. Some of these engagements make Mathematics seem more reflective oriented than English. At the level of the subjects employed here, English involves more of comprehension exercises and sentence construction. In this case, impulse control is important, but may not be critical especially in situations where the child knows the right approach. It will be prudent for further studies to compare the potency of cognitive modelling between Mathematics and English for clearer understanding of this issue.

\section{DISCUSSION, CONCLUSION AND RECOMMENDATION}

Cognitive thinking strategies normally develop before children enter adolescence, and childrens academic and social journey could be smooth if they adopt reflective thinking, not only for academic work but also for avoidance of risky decision-making. Pupils in the regular classrooms who are often set aside as underachievers and repeat classes, can function like their peers if they are given the needed assistance. This study suggests that a concerted formalised teaching and practice strategy is needed for children to get to the academic level expected by the general standard. For these children, mastery learning may be impossible unless they are formally trained how to learn. In recent educational reforms, the classroom is expected to practice inclusion of children with some level of special needs, including impulsivity. Teachers will need the help of proven alternative approaches to teaching and learning, such as the strategy used in this study. The cognitive behaviour modification strategies of cognitive modelling, used in this study has been effective for use in the Ghanaian classroom situation. The reflective characteristics acquired were sustained even to the delayed posttest. By itself, cognitive behaviour modification strategies for self-initiated appropriate attending to cognitive tasks will not eliminate a pupil's learning deficits. Neither will it guarantee that learners will fully make use of their cognitive skills. Educators still need to explore the world of children in search of answers to learning problems. This study investigated options for improving the academic performance of underachieving impulsive pupils. The results suggest the need for incorporating these strategies into the educational programs for all children. In our view, improvement in the children's problem solving ability may have been much higher and have lasted much longer if the intervention had been sustained for a longer period. It takes time and constant practice to learn strategies and develop automaticity in them.

Quite intriguing, previous assessments of impulsivity focussed on parents and teachers as key informants. The Vanderbilt Assessment Scale, which was adapted for this study assessed only those two groups as informants and employed the children themselves as informants, thus affirming the fact that they can recognize the negative behaviour of impulsivity within and assess themselves when given the opportunity. Another unique contribution of this study the use of a larger group to increase the power of the study and more importantly, Solomon four to test for testing pretest sensitisation effects. The reflective thinking strategies embedded in the intervention was seen in the increased scores after the behaviour modification training. It is important to note that the strategy delayed responding, even though merely delaying responses may not necessarily indicate reflectivity. This study proved that reflective thinking strategies are necessary for increasing problem solving and decision making. All children benefit from instruction, but some children need incredible amounts of careful, personal instruction, with clear and repeated demonstrations of how they should go about their learning and performance of cognitive tasks. Left without adequate demonstrations, struggling impulsive learners are likely to continue trying to make sense out of lessons, but rarely will they accomplish this feat. Besides giving impulsive children a new potential for performing, the strategy used in this study provides children with self-directed problem-solving techniques that increase the possibility for all children to maximise their learning potential for school success.

\section{Recommendations}

The problem of classroom impulsivity is too pronounced to be continually ignored in the Ghanaian primary schools. The condition yields undesirable consequences for children and cripple their academic achievement; the real essence of their being in school. It is therefore 
recommended that schools in collaboration with educational psychologists should organize remedial programmes for children where reflective practices could be taught and its importance emphasized. Teachers need to have clear knowledge of impulsive characteristics that are displayed in the classroom setting so that they could help identify such children before they graduate into other unmanageable disorders. The questionnaires used in this study could be a source of information to stakeholders. Parents and teachers should praise other children who demonstrate desirable behaviours in order to signal or draw other pupils' attention to what is expected of them in the classroom. Positive self-talks help to achieve target behaviours, and teachers can make use of that in the classroom. More important, teachers could be given training to increase their awareness of reflective teaching, avoid the barriers by having a clear understanding of reflective teaching and its implementation and improve its practice.

Other recommendations that could be made due to observations noted in the course of the study are: The Ghana Education Service stipulated maximum class size of 35 must be strictly enforced in order to restrict the spread of impulsivity among children (where a few exist in the classroom). Teachers must also learn to ignore children who blurt out appropriately or seek attention in impulsive and disruptive ways. Instead, apply the consequences of the behaviour plan. Also, the classroom should not contain fixed or permanent sitting places for children. The place a pupil sits during lessons should be based on the behaviour at that time. Teachers are expected to provide feedback on both the content and process of the learners' own reflective practice and provide an environment that encourages reflective practice Schools should invite resource persons like educational or cognitive psychologists to train teachers in reflective practices. Finally, curriculum developers may have to integrate the pedagogy of reflective teaching in trainee-teachers curriculum so that they are equip with such skills before they are placed in the classrooms.

Author contributions: All authors were involved in concept, design, collection of data, interpretation, writing, and critically revising the article. All authors approve final version of the article.

Funding: The authors received no financial support for the research and/or authorship of this article.

Declaration of interest: Authors declare no competing interest.

Data availability: Data generated or analysed during this study are available from the authors on request.

\section{REFERENCES}

Ammer, J. J. (1983). Teaching students how to learn: A self-instruction strategy to increase attending-to-task and problem-solving skills of underachieving middle school students. Middle School Research Selected Studies, 8(1), 70-85. https://doi.org/10.1080/ 08851700.1983.11670242

Asikhia, O. (2010). Students and teachers' perception of the causes of poor academic performance in Ogun State secondary schools [Nigeria]: Implications for counseling for national development. European Journal for Social Sciences, 13, 229-242.

Bandura, A. (1969). Principles of behaviour modification. Holt, Rinehart \& Winston.

Bandura, A. (1982). Self-efficacy mechanism in human agency. American Psychologist, 37, 122-147. https://doi.org/10.1037/0003066X.37.2.122
Bandura, A. J. (1977). Social learning theory. Prentice Hall.

Barkley, R. A. (1997). ADHD and the nature of self-control. Guilford Press.

Barkley, R. A. (2006). Attention deficit hyperactivity disorder: A handbook for diagnosis and treatment (3rd ed.). Guildford Press.

Cameron, M. I., \& Robinson, V. M. J. (1980). Effects of cognitive training on academic and on-task behaviour of hyperactive children. Journal of Abnormal Child Psychology, 8(3), 405-419. https://doi.org/10.1007/BF00916384

Cameron, R. (1984). Problem-solving inefficiency and conceptual tempo: A task analysis of underlying factors. Child Development, 55, 2031-2041. https://doi.org/10.2307/1129777

Carver, C. S. (2005). Impulse and constraint: Perspectives from personality psychology, convergence with theory in other areas, and potential for integration. Personality and Social Psychology Review, 9, 312-333. https://doi.org/10.1207/s15327957pspr0904_2

Debus, R. L. (1970). Effects of brief observation of model behaviour on conceptual tempo of impulsive children. Developmental Psychology, 2(1), 22-32. https://doi.org/10.1037/h0028603

Deliz, A. (2008). Causes of ADD/ADHD. http://abby.deliz.suite101.com/causes-of-addadhd-971672

DuPaul, G. J., Morgan, P. L., Farkas, G., Hillemeier, M. M., \& Maczuga, S. (2016). Academic and social functioning associated with attention-deficit/hyperactivity disorder: Latent class analyses of trajectories from kindergarten to fifth grade. Journal of Abnormal Child Psychology, 44, 1425-1438. https://doi.org/10.1007/s10802016-0126-z

Etsey, K. (2005). Causes of low academic performance of primary school pupils in the Shama Sub-Metro of Shama Ahanta East Metropolitan Assembly (SAEMA) in Ghana. Regional Conference on Education in West Africa, Dakar, Senegal.

Fontaine, R. G., \& Dodge, K. A. (2006). Real-time decision making and aggressive behaviour in youth: A heuristic model of response evaluation and decision (RED). Aggressive Behaviour, 32, 604-624. https://doi.org/10.1002/ab.20150

Franco, C., Amutio, A., Lopez-Gonzalez, L., Oriol, X., \& MatinezTaboada, C. (2016). Effect of a mindfulness trainingpProgram on the impulsivity and aggression levels of adolescents with behavioral problems in the classroom. Frontiers. in Psychology. https://doi.org/10.3389/fpsyg.2016.01385

Fredriksen, M., Dahl, A. A., Martinsen, E. W., Klungsoyr, O., Faraone, S. V., \& Peleikis, D. E. (2014). Childhood and persistent ADHD symptoms associated with educational failure and long-term occupational disability in adult ADHD. Attention Deficit and Hyperactivity Disorders, 6, 87-99. https://doi.org/10.1007/s12402014-0126-1

Gorrell, J. (1993). Cognitive modeling and implicit rules: Effects on problem-solving performance. The American Journal of Psychology, 106(1), 51-65. https://doi.org/10.2307/1422865

Haskins, R., \& McKinney, J. D. (1976). Relative effects of response tempo and accuracy on problem solving and academic achievement. Child Development, 47, 690-696. https://doi.org/10.2307/1128183

Herman, B. (1982). Treating cognitively impulsive children using academic materials and peer models (Unpublished doctoral dissertation), Indiana State University, U.S.A. 
Kagan, J. (1966). Reflection-impulsivity: The generality and dynamics of conceptual tempo. Journal of Abnormal Psychology, 71(1), 17-24. https://doi.org/10.1037/h0022886

Kagan, J., Pearson, L., \& Welch, L. (1966). Modifiability of an impulsive tempo. Journal of Educational Psychology, 57, 359-365. https://doi.org/10.1037/h0023960

Kangro, E. M. (2011). Interplay of self-control and situational demands in binge-drinking. Abstract submitted at the 2nd Biennial Meeting of the Association Research in Personality, Latvia. https://doi.org/10.1037/e676392012-158

Kano, D. D., Ayana, D. K., \& Chali, G. T. (2017). Practices and challenges on reflective teaching: An investigation of second cycle primary schools (5-8) EFL Teachers' in South West Cluster Zones of Oromiya Regional State. International Journal of Sciences: Basic and Applied Research (IJSBAR), 33(2), 225-247.

Kreisman, J. J., \& Hal Straus, M. D. (2004). Living with borderline personality disorder. John Wiley and Sons, Inc.

Lawry, J. A., Welsh, M. C., \& Jeffrey, W. E. (1983). Cognitive tempo and complex problem solving. Child Development, 54, 912-920. https://doi.org/10.2307/1129895

Nkrumah, I. K., \& Neumann, E. (2017). Cross-language negative priming remains intact, while positive priming disappears: evidence for two sources of selective inhibition. Journal of Cognitive Psychology, 30(3), 361-384. https://doi.org/10.1080/20445911. 2017.1417311

Nkrumah, I., Olawuyi B., \& Torto-Seidu, E. (2015). Effect of cognitive modelling on impulsive behaviour among primary school children. Psychology and Behavioural Sciences; 4(5), 174-180. https://doi.org/10.11648/j.pbs.20150405.11

Nkrumah, K, I. (2013). Effect of cognitive modelling on impulsive behaviour among primary school children (Unpublished MPhil thesis), University of Illorin, Nigeria.

Nwamuo, P. A. (2010). The effect of cognitive modelling in the reduction of impulsive behaviour among primary school children. Ife Psychologia. https://doi.org/10.4314/ifep.v18i1.51653

Odoemelam, A. L. (1994). The effects of selected treatment programmes on the behaviour problems of primary school children in Owerri urban, Imo State (Unpublished PhD thesis), University of Nigeria, Nsukka.

Olasehinde, F. A. O. (1986). The relationship of cognitive style dimension of impulsivity/reflective with sex, creativity and achievement (M. Ed. thesis), University of Ilorin, Nigeria.

Olasehinde, F. A. O. (1992). Development and assessment of procedures for training inreflective thinking in cognitive task performance. Nigerian Journal of Educational Foundations, 3(1), 123131.
Olasehinde, F. A. O. A. (1991). Assessment of procedures for training in reflective thinking in cognitive task performance (Unpublished $\mathrm{PhD}$ thesis), University of Ilorin, Nigeria.

Peckham, A. D, Johnson, S. L, \& Swerdlow, B. A. (2019). Working memory interacts with emotion regulation to predict symptoms of mania. Psychiatry Research, 281, 112551. https://doi.org/10.1016/j.psychres.2019.112551

Pedersen, S., \& Liu, M. (2002). The effects of modelling expert cognitive strategies during problem-based learning. Journal of Educational Computing Research, 26(4), 353-380. https://doi.org/10.1092/8946J9N7-E79U-M7CR

Pourmohamadreza-Tajrishi, M., Ashori, M., \& Jalil-Abkenar, S. (2015). The effectiveness of verbal self-instruction training on math problem-solving of intellectually disabled students. Iranian Rehabilitation Journal, 13(4), 58-62.

Schunk, D. H. (1981). Modelling and attributional effects on children's achievement: A self-efficacy analysis. Journal of Educational Psychology, 73, 93-105. https://doi.org/10.1037/0022-0663.73.1.93

Schunk, D. H., \& Hanson, A. R. (1985). Peer models: Influence on children's self-efficacy and achievement. Journal of Educational Psychology, 77, 313-322. https://doi.org/10.1037/00220663.77.3.313

Special Attention Project. (2011). Children with learning difficulties in public basic schools in Ghana. A study involving local stakeholders in Greater Accra region. http://docsgoogle.com/viewer?acache: EvifwrMkBS:sapghana.com/data

Spinella, M., \& Miley, W. M. (2003). Impulsivity and academic achievement in college students. College Student Journal, 37(4), 545549.

Valentine, J. C., Harris Cooper, H., Patall, E. A., Tyson, D., \& Robinson, J. C. (2010). A method for evaluating research syntheses: The quality, conclusions, and consensus of 12 syntheses of the effects of after-school programs. Research Synthesis Methods, 1(1), 20-38. https://doi.org/10.1002/jrsm3

Werbach, M. R. (1995). Nutritional influences of aggressive behaviour. Journal of Orthomolecular Medicine, 7(1). http://orthomolecular.org/library/articles/webach.shtml

Woods, K., \& Ploof, H. (1997). Understanding ADHD: Attention deficit disorder and the feeding brain. SAGE.

Yando, R., \& Kagan, J. (1968). The effect of teacher tempo on the child. Child Development, 39, 27-34. https://doi.org/10.2307/1127355

Zapolski, T. C. B., Cyders, M. A., \& Gregory, T. S. (2009). Positive urgency predicts illegal drug use and risky sexual behaviour. Psychology of Addictive Behaviour, 32, 348-354. https://doi.org/10.1037/a0014684 